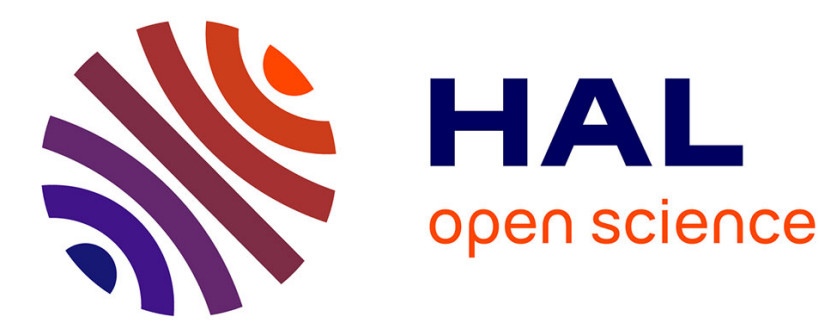

\title{
Evaluating Teachers' Perceptions of Students' Questions Organization
}

\author{
Fatima Harrak, François Bouchet, Vanda Luengo, Pierre Gillois
}

\section{To cite this version:}

Fatima Harrak, François Bouchet, Vanda Luengo, Pierre Gillois. Evaluating Teachers' Perceptions of Students' Questions Organization. Learning Analytics \& Knowledge Conference, Mar 2020, Frankfurt, Germany. pp.11-16, 10.1145/3375462.3375509 . hal-02422186

\section{HAL Id: hal-02422186 \\ https://hal.science/hal-02422186}

Submitted on 25 Mar 2020

HAL is a multi-disciplinary open access archive for the deposit and dissemination of scientific research documents, whether they are published or not. The documents may come from teaching and research institutions in France or abroad, or from public or private research centers.
L'archive ouverte pluridisciplinaire HAL, est destinée au dépôt et à la diffusion de documents scientifiques de niveau recherche, publiés ou non, émanant des établissements d'enseignement et de recherche français ou étrangers, des laboratoires publics ou privés. 


\section{Evaluating Teachers' Perceptions of Students' Questions Organization}

\author{
Fatima Harrak \\ Sorbonne Université \\ CNRS, LIP6, F-75005 Paris, France \\ fatima.harrak@lip6.fr \\ Vanda Luengo \\ Sorbonne Université \\ CNRS, LIP6, F-75005 Paris, France \\ vanda.luengo@lip6.fr
}

\author{
François Bouchet \\ Sorbonne Université \\ CNRS, LIP6, F-75005 Paris, France \\ francois.bouchet@lip6.fr \\ Pierre Gillois \\ Université Grenoble Alpes \\ 38400 Saint-Martin-d'Hères, France \\ pierre.gillois@univ-grenoble-alpes.fr
}

\begin{abstract}
Students' questions are essential to help teachers in assessing their understanding and adapting their pedagogy. However, in a flipped classroom context where many questions are asked online to be addressed in class, selecting questions can be difficult for teachers. To help them in this task, we present here three alternative ways of organizing questions: one based on pedagogical needs, one based on estimated students' profiles and one mixing both approaches. Results of a survey filled by 37 teachers in a flipped classroom pedagogy show no consensus over a single organization. A cluster analysis based on teachers' flipped classroom experience allowed us to distinguish two profiles, but they were not associated with any particular question organization preference. Qualitative results suggest the need for different organizations may rely more on a pedagogical philosophy and advocates for differentiated dashboards.
\end{abstract}

\section{CCS CONCEPTS}

\section{- Applied computing $\rightarrow$ E-learning.}

\section{KEYWORDS}

Teacher's perception, question organization, student's need, student's question, student's profile, pedagogical interest

\section{ACM Reference Format:}

Fatima Harrak, François Bouchet, Vanda Luengo, and Pierre Gillois. 2020. Evaluating Teachers' Perceptions of Students' Questions Organization. In Proceedings of the 10th International Conference on Learning Analytics and Knowledge (LAK '20), March 23-27, 2020, Frankfurt, Germany. ACM, New York, NY, USA, 6 pages. https://doi.org/10.1145/3375462.3375509

\section{INTRODUCTION}

Student-teacher interaction allows students to ask questions, practice free expression of ideas, develop their own skills and improve

Permission to make digital or hard copies of all or part of this work for personal or classroom use is granted without fee provided that copies are not made or distributed for profit or commercial advantage and that copies bear this notice and the full citation on the first page. Copyrights for components of this work owned by others than ACM must be honored. Abstracting with credit is permitted. To copy otherwise, or republish, to post on servers or to redistribute to lists, requires prior specific permission and/or a fee. Request permissions from permissions@acm.org.

LAK '20, March 23-27, 2020, Frankfurt, Germany

(c) 2020 Association for Computing Machinery.

ACM ISBN 978-1-4503-7712-6/20/03 . \$ \$15.00

https://doi.org/10.1145/3375462.3375509 class [14]. Teachers have to adapt their discourses to students' pedagogical needs, which can be particularly challenging in a university context with large cohorts of students. Blended learning can be one way to tackle this challenge, as it offers an opportunity to give more time to essential student-teacher interactions [3]. However, dealing with students' questions asked online and sent by email to teachers can be a difficult task, due to the volume of questions asked and the way they are presented (list of questions, with the number of votes received per question). In order to provide teachers with additional information to help them choose questions for their Q\&A session, we envisioned alternative ways of organizing questions, with a structure that depends on students' needs (based on the nature of the questions they ask) or students' profiles (based on what we know of previous students who asked similar questions, in particular in terms of performance in the course). As a preliminary step, we conducted a survey to evaluate the teachers' use of the current system and their perceptions of various alternative questions' organization systems, to answer to the following research question: which type of question organization best fits the needs of teachers to prepare their Q\&A session in a blended learning context?

\section{RELATED WORK}

The topic of students' questions and how to leverage learning analytics approaches to help teachers in choosing which one to address has, to the authors' knowledge, not been much explored in the learning analytics community. Indeed, in their recent analysis of the use of Natural Language Processing (NLP) techniques for learning analytics, McNamara et al. [12] mostly mention students' questions in two contexts: providing an automatic answer to them (with systems like AutoTutor [4] or iSTART [13]), or examining how it relates to a reference text (with tools such as ReaderBench [1]). Therefore, providing a comprehensive visualization of students' questions seems to be a largely ignored issue.

Our approach here relies on the use of an acceptance survey for a redesigned interface of an existing "tool" used in blended learning. This is a typical approach in human-centered design, similar to the one used in [9] where researchers investigated teacher-perceived experience and acceptance of a recommender system in the context of online and blended learning.

We will compare here two approaches that rely respectively on increasing the visibility of students' pedagogical needs (based on 
the questions asked) and students' profiles, which both have distinct values and advantages. On the one hand, teachers are expected to understand the learning process in order to design and implement teaching methods aligned with students' needs that enhance learning [8]. Works such as [10] and [15] have focused on helping teachers in having a better understanding of their students' needs, which helped in increasing students' performance. On the other hand, showing visualizations of how some students are doing better or worse than others, such as in [2] or [11], can help the teachers in allocating their time to students in a fairer manner than if they do not have access to that information.

\section{PEDAGOGICAL CONTEXT}

The Faculty of Medicine and Pharmacy of a large French public university has a specific hybrid training system (reading of the material for the class is done at home, and classroom time is dedicated mostly to Q\&A) for their first year students. The first year is divided into two semesters, each of them ending with a competitive exam (in January and May): only a predefined number of students is allowed to continue in the second year. After having read the pedagogical content at home, the students connect to an online platform to ask a question and/or see questions from other students? They can vote for a question if they also want an answer to it, but not answer to them. Then, the questions asked online are sent to teachers by email to help them prepare their Q\&A face-to-face session.

\subsection{The need for alternative organizations}

The only additional information currently provided to teachers is the number of votes on each question. Interviews with involved teachers previously revealed several shortcomings with the current approach. The main issue is that the amount of questions, presented in an unstructured manner, can be overwhelming. Moreover, the number of votes can lead to an easy yet not necessarily optimal approach which consists in answering to the most popular questions first, which may not be the most pedagogically interesting. Moreover, due to the competitive nature of the training, a minority of students (usually the ones following the course for the second time) sometimes ask deliberately obscure questions to confuse others. All these observations suggest it would be worth investigating alternative ways to organize and present the list of students' questions to the teachers in their weekly email report.

\subsection{Proposal of alternative organizations}

In order to provide alternative questions organizations, we rely on a coding scheme introduced by [7] which allows to tag questions along several dimensions in terms of pedagogical needs, according to 4 independent dimensions: a main mandatory one (dimension 1) and 3 optional ones (dimensions 2 to 4). In [5], the authors provided and evaluated a set of tools to automatically tag students' questions according to that coding scheme (with an average Kappa of 0.70 ), opening up the possibility to use it on other datasets. This work can therefore be used to automatically categorize the students' questions for instance in terms of "request for a re-explanation" vs. "need to deepen a concept".

Additionally, in [6], the same coding scheme was used to cluster students' questions and associate some students' characteristics to these clusters (those characteristics include grades, attendance or retaking the class). An interesting aspect of this work is the fact that the authors show the clusters seem to remain constant across several years. It is thus possible to make assumptions on the profile of a student asking a set of questions on year $\mathrm{N}$ based on the profiles of students who asked similar questions on year N-1. One can therefore provide teachers with additional information about the students asking questions, even if no grades are available yet.

Using the two aforementioned works, we could envision three alternative questions organizations, illustrated with 8 sample questions (translated from French) presented in Figures 1 to 3:

- an organization based on students' pedagogical needs (PN), in which the questions are grouped according to the main dimension of the coding scheme, and then according to the other three dimensions. For instance, a question could be a request to reexplain the way something works. It could also be a request to verify if a schema needs to be memorized for the final exam. The nature of the questions asked (Re-explanation, Deepening, verification or Other, which corresponds to dimension 1 and 4 in the coding scheme), as indicated by the keywords in bold in Figure 1.

- an organization based on the predicted students' profile (PP), where students' questions are grouped according to the profile of students who asked these types of questions on previous years. The mention "grades below average" is therefore not based on the grades of students who ask the questions, and could be available early on (cf. Figure 2).

- a mixed organization (M), combining the two information previously presented: the type of questions asked by the student and an estimation of their level (cf. Figure 3).

\section{SURVEY}

To evaluate the potential of the three alternative organizations and teachers' interests in them, we conducted a survey made of 28 questions ${ }^{1}$. The survey was done through LimeSurvey and sent to teachers involved in the aforementioned hybrid training system.

\subsection{Survey content}

The first part of the survey consisted in evaluating the teachers' experience with the Q\&A session and their appreciation of the flipped classroom approach. We will briefly present the various questions asked to the teachers in this part.

The survey starts with questions related to the number of questions received $[\mathrm{NbQ}]$ and the proportion of questions addressed [PropQ], followed by a series of 7 statements regarding the questions received by email and for which a degree of agreement is measured on a scale from 1 to 5 (where $1=$ "strongly disagree" and 5 = "strongly agree").

- feeling of receiving too many questions $[\mathrm{Rq}+]$

- feeling of not receiving enough questions [Rq-]

- disorganization [Dis]

- lack of usefulness for the Q\&A session [Use-]

- interesting [Int]

- related to the course [RelCou]

- novelty (compared to previous years)[New]

${ }^{1}$ Available in French as PDF there: https://hal.archives-ouvertes.fr/hal-02422186 


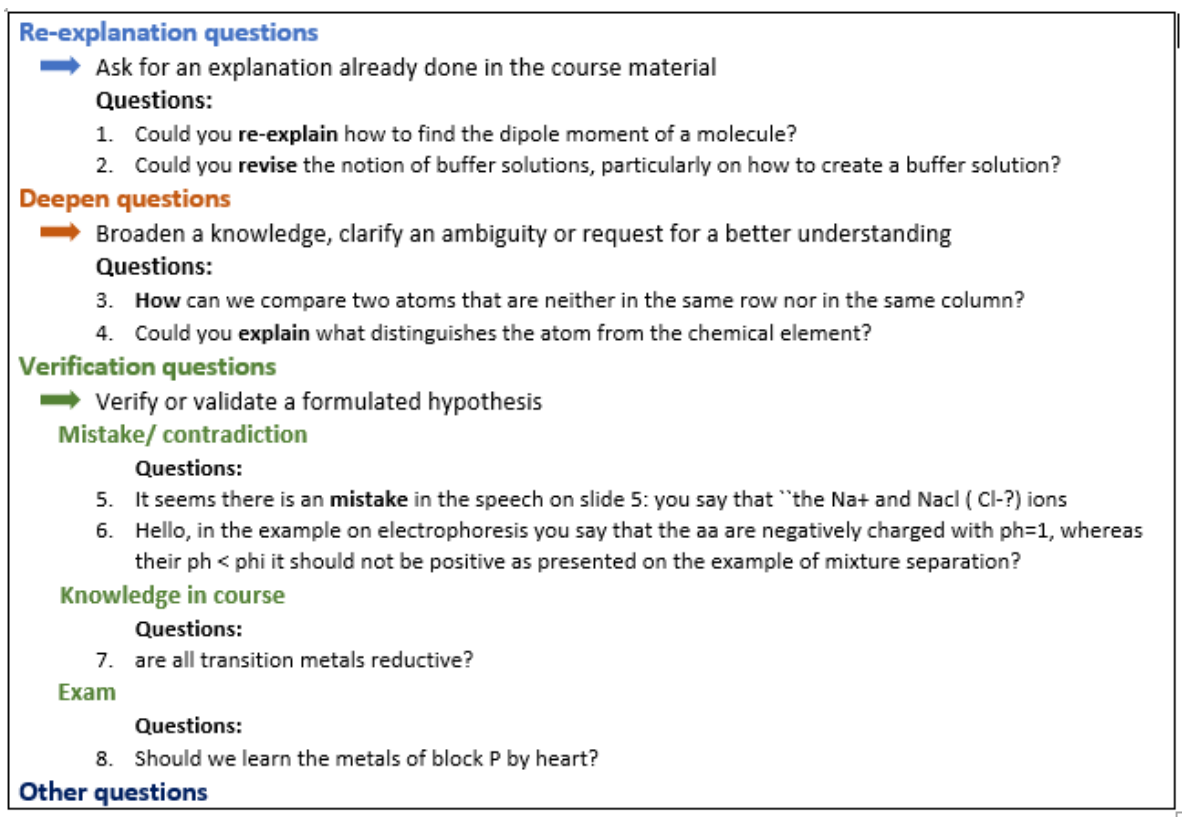

Figure 1: Example of the organization based on the students' pedagogical needs (PN)

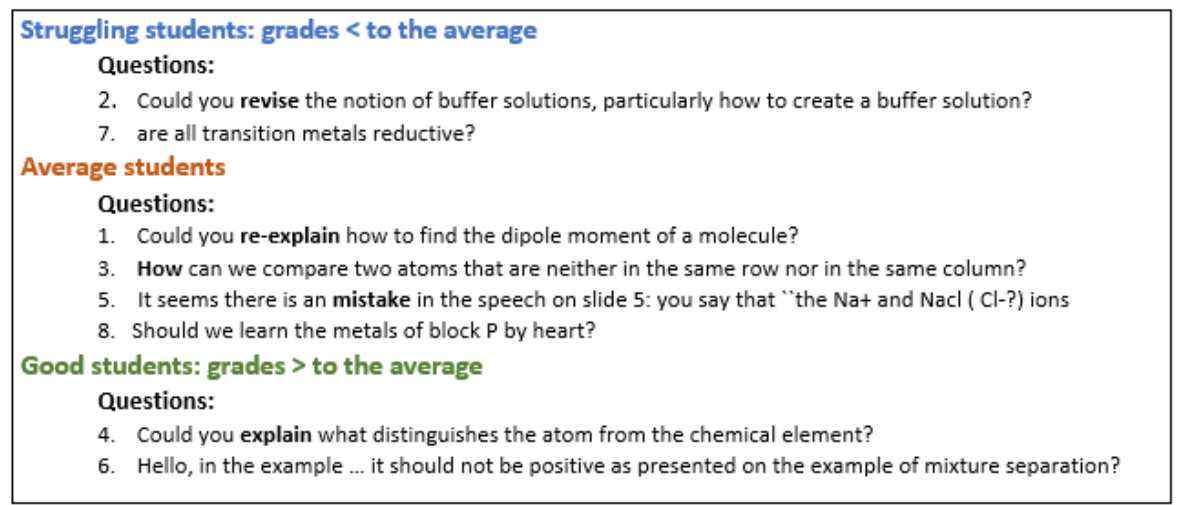

Figure 2: Example of the organization based on the predicted students' profile (PP)

\begin{tabular}{|c|c|c|c|c|}
\hline $\mathbf{N}$ & Re-explain questions & Struggling & Average & Good \\
\hline $\begin{array}{l}1 . \\
2 .\end{array}$ & $\begin{array}{l}\text { Could you re-explain how to find the dipole moment of a molecule? } \\
\text { Could you revise the notion of buffer solutions, particularly on how ...? }\end{array}$ & $\begin{array}{l}\mathrm{X} \\
\mathrm{X} \\
\end{array}$ & & \\
\hline $\mathbf{N}$ & Deepen questions & Struggling & Average & Good \\
\hline 3. & $\begin{array}{l}\text { How can we compare two atoms that are neither in the same row ...? } \\
\text { Could you explain what distinguishes the atom from the chemical element? }\end{array}$ & & $\begin{array}{l}\mathrm{X} \\
\mathrm{X}\end{array}$ & \\
\hline $\mathbf{N}$ & Verification questions & Struggling & Average & Good \\
\hline $\begin{array}{l}5 . \\
6 . \\
7 . \\
7 .\end{array}$ & $\begin{array}{l}\text { - Mistake/ contradiction } \\
\text { It seems there is an mistake in the speech on slide 5: you say that ... } \\
\text { Hello, in the example on electrophoresis you say that the aa ...? } \\
\text { - Knowledge in course } \\
\text { are all transition metals reductive? } \\
\text { Should we learn the metals of block P by heart? }\end{array}$ & & $\mathrm{x}$ & $\begin{array}{l}x \\
x\end{array}$ \\
\hline
\end{tabular}

Figure 3: Example of the mixed organization (M) combining PN and PP organizations 
$\left[\mathrm{Rq}^{+}\right]$and $\left[\mathrm{Rq}^{-}\right]$provide a subjective measure, as opposed to [NbQ] which is more objective (e.g., a teacher can be overwhelmed with 10 questions when another finds that 30 are not enough).

Three statements about flipped pedagogy are measured by a degree of agreement on a scale of 1 to 5 .

- facility of teaching in a hybrid classroom [Fac]

- organizational appreciation [Org]

- saving time and energy [Tim]

The second part of the survey consisted in evaluating teachers' perception of questions' organization. Each organization is supported by a series of statements with a level of associated agreement measured on a Likert scale from 1 to 5 :

- ease of understanding [EasO]

- interest for the organization [IntO] (the usefulness of additional information to prepare the Q\&A session)

Respondents were also asked for each question organization how they would consider using the categories presented in their Q\&A session, how they ranked it compared to what they currently receive (better, same, worse) and if there were areas for improvement (open question). At the end, teachers were asked to choose a single favorite organization between four possible choices: the 3 proposed ones (PN, PP and $\mathrm{M}$ ) and the current one.

\subsection{Participants' demographics and experience}

The survey was sent to 58 teachers, 37 of whom replied to all the questions. We also filtered the outliers, replaced the missing values from the survey, and removed one respondent who stated not using the questions received to prepare the Q\&A session and is therefore not involved in the system to be evaluated. For the missing data, although one teacher failed to specify his teaching seniority, we attributed a value ([5-10]) based on responses given by the majority of teachers of his age. The "seniority" [Sen] variable was recoded into categories (ranges) to help in replacing missing values.

The descriptive statistics ( $N=36$ teachers, see Table 1$)$ showed a wide variety of age (34 to 69) and seniority, as well as teachers involved in almost all the courses (represented by their acronyms). Furthermore, the overall response time is large enough to consider the responses are valid, an assumption confirmed by the fact that $92 \%$ of teachers have also taken the time to leave comments. Table 2 provides a summary of the descriptive statistics for each variable according to teachers' responses in part I of the survey.

In terms of teachers' experience in Q\&A session, they considered they were receiving a moderate amount of questions which they perceived as disorganized but useful for the Q\&A preparation. They are split between those receiving too many questions (15 teachers answering 4 or 5), and those thinking they do not receive enough ( 9 teachers answering 4 or 5). Overall, they feel the questions are similar from one year to the next (not much novelty), moderately interesting and on-topic. Moreover, a majority believe that they actually handle more than $80 \%$ of the questions received by e-mail during the Q\&A session (e.g., Teacher29 states: "The questions are repeated and are not pedagogically relevant due to the diversity of the audiences. Very limited time"). In terms of teachers' perception of the flipped classroom, they appreciated the facility of teaching in a hybrid classroom and its organization, but did not really feel like it was saving them any time.

\section{PREFERRED ORGANIZATION ANALYSIS}

\subsection{Method}

To evaluate the usefulness of an alternative questions' organization system, we showed different type of questions' organizations to teachers (cf. Figures 1, 2 and 3). The design of these organizations is based on the nature of questions asked by students and their profiles in terms of performance. We focused on the main question categories from the coding scheme introduced in [7] to keep the organizations easy to read and limit information overload.

\subsection{Results}

The results of teachers' responses in part II of the survey, summarized in Table 3, showed that no consensus over a particular organization. Indeed, the final choice of teachers was divided equally between the organization based on pedagogical needs $(\mathrm{PN}-N=11)$, the one mixing pedagogical needs and profiles $(M-N=11)$ and the current one $(N=11)$, whereas the one based only on students' profiles (PP) was chosen by only three teachers.

\subsection{Discussion}

"PN" organization was the most appreciated by teachers (19 teachers preferred it to the current organization), but the qualitative analysis of the comments associated with it shows some teachers did not fully understand how it would be created, assuming that it would be the students who would have to tag their questions when asking them, which they may struggle at. Without this perceived limit, we can assume a larger number of teachers might have positively assessed it. (e.g., Teacher08 "... This organization may have the merit of making the student think more about the type of question she is asking, (...) this system will only work if used correctly by students.)

Some teachers already have ideas on the use of the questions asked in each category (e.g., Teacher25: "I believe this mode of organization corresponds more or less to the treatment I perform when I receive them...", "Case 1: I explain again, but with another approach... Case 2: I deepen, precise, clarify, explain! making sure to consolidate the initial objective in this way... Case $n^{\circ} 3$ : dream case! helps to understand how the student did not understand, and helps to bring them back to the right concept...)"). Others were more sceptical about its use (e.g., Teacher10: "I will try to answer to all of them, regardless of this categorization and in chronological order with respect to the course..."). It is worth noting though that this particular comment could apply to all the alternative questions' organization proposed, and maybe a chronological organization would make more sense for them (based on the slide number associated to the question).

Interestingly, the "PP" organization is clearly the least appreciated of the three. Some teachers thought they would use it by answering to questions from struggling students first, and then to questions from good ones. But many judged it less valuable than the current one, assuming the hidden purpose was to respond first to good students and were concerned about the fairness of the proposal (although nothing in the organization suggested favouring this approach, as the questions of struggling students were presented first). Some were opposed or worried because of the potential temptation (for them or for colleagues) to answer only to 


\begin{tabular}{|c|c|c|c|c|c|c|c|c|c|c|c|c|c|c|c|c|c|c|c|}
\hline \multicolumn{2}{|c|}{ Response time (s) } & \multicolumn{2}{|c|}{ Age } & \multicolumn{13}{|c|}{ Course taught } & \multicolumn{3}{|c|}{ Seniority } \\
\hline Mean & $\sigma^{2}$ & Mean & $\sigma^{2}$ & ANT & $|\mathrm{BCE}|$ & $|\mathrm{BCH}|$ & $|\mathrm{BPH}|$ & $\mid$ BSTAT $\mid$ & $|\mathrm{HBD}|$ & $\mathrm{ICM}$ & $\mid$ MAIEU $\mid$ & T MAT $\mid$ & $\mid$ ODON $\mid$ & |PHAR | & $|\mathrm{PHS}|$ & $|\mathrm{SSH}|$ & {$[1-5]$} & $\mid] 5-10] \mid$ & |]10+] \\
\hline 1044 & 618.15 & 48.25 & $|9.79|$ & 4 & 4 & 5 & 4 & 1 & 4 & 2 & 2 & 1 & 0 & 3 & 4 & 4 & 11 & 13 & 12 \\
\hline
\end{tabular}

Table 1: Descriptive statistics of the respondent population in terms of response time, age and course taught and seniority

\begin{tabular}{|c|c|c|c|c|c|c|c|c|c|c|}
\hline & $\mathrm{Rq}^{+}$ & $\mathrm{Rq}^{-}$ & Dis & Use- & Int & RelCou & New & Fac & Org & Tim \\
\hline Mean & 2.73 & 2.24 & 3.35 & 2.32 & 2.78 & 3.70 & 1.84 & 4.03 & 3.89 & 2.81 \\
\hline Std & 1.47 & 1.32 & 1.38 & 1.20 & 0.95 & 1.05 & 0.99 & 1.01 & 1.02 & 1.29 \\
\hline
\end{tabular}

Table 2: Summary of mean and standard deviation of scores given by teachers to each variable in the first part of survey

\begin{tabular}{ccccc}
\hline Organization & Worse & Same & Better & Nb of finale choice \\
\hline PN & 5 & 12 & 19 & 11 \\
PP & 15 & 16 & 5 & 3 \\
M & 10 & 12 & 14 & 11 \\
\hline
\end{tabular}

Table 3: Characteristics of 3 proposed organizations compared to the current one

questions from good students (e.g., Teacher27: "I am not for favoring the good over the struggling ones (this is a risk), our goal is to help them all"). Finally, a potential improvement proposed by the teachers would be to also take into account the level of the students who vote on questions, and not only those who ask the questions.

The teachers' opinion of the mixed ("M") organization was contradictory: 11 chose it as their preferred one yet found it difficult to read, recommending to focus only on one aspect. Some described it as "a bad method added to a good one" (Teacher44 - who was against showing students' levels) and even those who chose it were not sure to use it (Teacher24: Other than the fact that I am not sure to use it, I am not sure the textual analysis always provide a relevant classification... so let's do a mixed analysis and everyone will use it as they see fit). That comment shows an interest for flexibility, allowing each teacher to focus on the aspect relevant for them.

The quantitative and qualitative analysis of teachers' responses in part II revealed a clear difference in the choice of organizations. It may therefore be worth proposing different organizations for different types of teachers. Although one could provide all organizations and let each teacher choose the one they wanted (as suggested by Teacher 24), we wondered if those differences in choices came from a difference in teachers' profiles. This led us to ask the following follow-up research question: are the differences in teachers' organizations choices related to their different Q\&A session experience or their perception of the flipped classroom?

\section{PREFERRED ORGANIZATION ACCORDING TO THE TEACHERS' BACKGROUND}

\subsection{Method}

We performed clustering analyses using X-Means algorithm (with $k$ between 2 and 10, averaging 5 iterations with the same $k$ ), a variant of K-Means automating the choice of $k$ using BIC scores, over the set of explanatory variables rather than testing each one individually to take into account different aspects of teachers' experience in Q\&A session. We used as characteristics for each teacher the variables (cf. section 4.1) describing the set of questions received by email $([\mathrm{Rq}+]$, [Dis], [Use-], [Int], [RelCou], [New], [NbQ], [PropQ], excluding [Rq] which appeared to be strongly correlated with $[\mathrm{Rq}+])$, the variables related to flipped classroom experience ([Fac], [Org], [Tim]) and their seniority [Sen]. The variables are normalized between 0 and 1, except for NbQ (3 ranges), PropQ (5 ranges) and Sen (recoded into 3 ranges), which are categorical variables (cf. Table 4).

To characterize the clusters, we used variables related to the organizations' choices for each teacher. For each cluster, we calculated the average of EasO (score between 1 and 5) and the average of IntO (score between 1 and 5) for each organization. We also characterized each cluster according to the teachers' assessment of each of the 3 proposed organizations (worse, same, better) and the final choice ("PN", "PP", "M" and current).

\subsection{Results}

The best clustering was made of two very distinct clusters of teachers in terms of characteristics (cf. Table 4).

Cluster $1(N=22)$ is characterized by less experienced teachers, who like less the flipped classroom approach (low Fac and Org), receive more questions (more than $50 \%$ receive more than 50 questions per session) and handle less questions in their Q\&A session. They consider the questions received are very disorganized, moderately useful for their session and less relevant.

Cluster $2(N=14)$ represents more experienced teachers, who like the flipped classroom approach (high Fac and Org), receive few questions (between 1 and 50 questions received per session) and deal with the majority of questions asked. They consider the questions received by email are less disorganized, useful for the Q\&A session and moderately relevant.

\subsection{Discussion}

The analysis of clusters' characteristics presented in Table 5 did not reveal any clear differences in the choices made by the teachers of the two clusters. We only noticed a slight preference for the PN organization by teachers of cluster 1 , who seem on the contrary less convinced by the two organizations taking into account the estimated level of the student asking the question (PP and M).

Unfortunately, teachers' experience in Q\&A session and flipped classroom did not allow us to distinguish any differences in organizations' choices made by teachers. Some aforementioned difficulties such as problems in understanding an organization or cultural biases (feeling one should give equal attention to all students $v s$. needing to focus on the students' for whom one can have the highest impact), may affect the preference of organizations. We also 


\begin{tabular}{|c|c|c|c|c|c|c|c|c|c|c|c|c|c|c|c|c|c|c|}
\hline Clus & Fac & Org Tim & Dis & Use- $\mathbf{R q}+$ & Int & RelCou & New & [1-5] & $\begin{array}{c}\text { Sen } \\
] 5-10]\end{array}$ & ]$+10]$ & {$[1-20]$} & $\begin{array}{c}\text { NbQ } \\
\text { ] ]20-50] }\end{array}$ & ] ]+50] & $\mid<20 \% 2$ & $20-40 \%$ & $\begin{array}{r}\text { PropQ } \\
640-60 \%\end{array}$ & $60-80 \%$ & $>80 \%$ \\
\hline $\mathrm{C} 1$ & 0.576 & 0.5000 .466 & 0.739 & 0.4320 .557 & 0.364 & 0.761 & 0.242 & 5 & 12 & 5 & 5 & 5 & 12 & 1 & 2 & 2 & 9 & 8 \\
\hline $\mathrm{C} 2$ & 0.857 & 0.8570 .429 & 0.393 & 0.1960 .214 & 0.554 & 0.571 & 0.333 & 6 & 1 & 7 & 6 & 8 & 0 & 0 & 2 & 1 & 1 & 10 \\
\hline
\end{tabular}

Table 4: Centroids (distribution of respondents) of the variables associated to each cluster

\begin{tabular}{|c|c|c|c|}
\hline \multicolumn{2}{|c|}{ Variables } & \multirow{2}{*}{$\frac{\text { Cluster } \mathbf{1}(\mathbf{N}=\mathbf{2 2})}{4.273}$} & \multirow{2}{*}{$\frac{\text { Cluster2 }(\mathrm{N}=\mathbf{1 4})}{4.143}$} \\
\hline \multirow{5}{*}{ 允 } & EasO & & \\
\hline & IntO & 3.545 & 3.286 \\
\hline & Worse & 3 & 2 \\
\hline & Same & 8 & 4 \\
\hline & Better & 11 & 8 \\
\hline \multirow{5}{*}{ 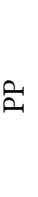 } & $\mathrm{EasO}$ & 3.545 & 4.071 \\
\hline & IntO & 2.227 & 2.643 \\
\hline & Worse & 10 & 5 \\
\hline & Same & 9 & 7 \\
\hline & Better & 3 & 2 \\
\hline \multirow{5}{*}{$\Sigma$} & $\mathrm{EasO}$ & 3.455 & 3.786 \\
\hline & IntO & 2.864 & 3.429 \\
\hline & Worse & 7 & 3 \\
\hline & Same & 8 & 4 \\
\hline & Better & 7 & 7 \\
\hline \multirow{4}{*}{ 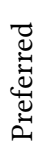 } & $\mathrm{PN}$ & 7 & 4 \\
\hline & $\mathrm{PP}$ & 2 & 1 \\
\hline & M & 6 & 5 \\
\hline & Current & 7 & 4 \\
\hline
\end{tabular}

Table 5: Characteristics of clusters in terms of dependent variables for each organization: Mean (EasO IntO) and distribution of respondents

believe other factors (beyond the Q\&A experience) may explain the differences in organizations' choices (e.g., teachers with ideas on how to use questions in each category $v s$. those who do not).

\section{CONCLUSION}

We presented here the results of a survey to evaluate teachers' perception of different students' questions organization sent to them to prepare their Q\&A sessions in a flipped classroom context. The results are split between the organization based on the pedagogical needs' according to an analysis of the nature of the questions, the same analysis that adds in information about the students' level (based on profiles from previous years) and the current one. Those preferences did not seem to be directly associated to teachers' experience overall or with the flipped classroom.

To conclude, although teachers approved the importance of students' questions to adapt their courses and strategies, the difficulty for choosing a relevant questions' organization remains. This work could be used to provide teachers with a valuable source of inspiration about how to deal with students' questions which also favor a better understanding of their needs to increase their engagement

and improve the learning process. One of the limits of this work relies on the fact some teachers have misinterpreted some of the questions asked and the principle of the proposed organizations. Alternative visualization variants for each organization can also easily be imagined. Thinking about the future of Learning Analytics, we believe the current result advocates for the trend towards personalized dashboards instead of "one size fits all", depending on the pedagogical philosophy of the teachers. We also believe this personalization can be at least partially automatized based on what we know of the teachers' profile and teaching philosophy.

\section{REFERENCES}

[1] Mihai Dascalu, Philippe Dessus, Maryse Bianco, Stefan Trausan-Matu, and Aurélie Nardy. 2014. Mining Texts, Learner Productions and Strategies with ReaderBench. In Educational Data Mining: Applications and Trends, Alejandro Peña-Ayala (Ed.). Springer Int. Publishing, Cham, 345-377.

[2] Alfred Essa and Hanan Ayad. 2012. Student Success System: Risk Analytics and Data Visualization Using Ensembles of Predictive Models. In Proc. of the Int. Conf. on Learning Analytics and Knowledge (LAK '12). ACM, NY, USA, 158-161.

[3] Pierre Gillois, Jean-Luc Bosson, Celine Genty, Jean-Philippe Vuillez, and JeanPaul Romanet. 2015. The impacts of blended learning design in first year medical studies. Studies in Health Technology and Informatics (2015), 607-611.

[4] Arthur C. Graesser. 2016. Conversations with AutoTutor Help Students Learn. Int. Fournal of Artificial Intelligence in Education 26, 1 (March 2016), 124-132.

[5] Fatima Harrak, François Bouchet, and Vanda Luengo. 2019. Categorizing students' questions using an ensemble hybrid approach. In Educational Data Mining. Montréal, Canada.

[6] Fatima Harrak, François Bouchet, and Vanda Luengo. 2019. From Students' Questions to Students' Profiles in a Blended Learning Environment. Fournal of Learning Analytics 6, 1 (April 2019), 54-84-54-84.

[7] Fatima Harrak, François Bouchet, Vanda Luengo, and Pierre Gillois. 2018. Profiling Students from Their Questions in a Blended Learning Environment. In Proc. of the 8th Int. Conf. on Learning Analytics and Knowledge (LAK '18). ACM, Sydney, Australia, 102-110.

[8] Cathy H. C. Hsu. 1999. Learning styles of hospitality students: Nature or nurture? Int Journal of Hospitality Management 18, 1 (March 1999), 17-30.

[9] Soultana Karga and Maya Satratzemi. 2019. Evaluating Teachers' Perceptions of Learning Design Recommender Systems. In Transforming Learning with Meaningful Technologies, Vol. 11722. Springer Int. Publishing, Cham, 98-111.

[10] Katharina Kiemer, Alexander Gröschner, Ann-Kathrin Pehmer, and Tina Seidel. 2015. Effects of a classroom discourse intervention on teachers' practice and students' motivation to learn mathematics and science. Learning and Instruction 35 (Feb. 2015), 94-103.

[11] Steven Lonn and Stephanie D. Teasley. 2014. Student Explorer: A Tool for Supporting Academic Advising at Scale. In Proceedings of the First ACM Conf. on Learning@ Scale Conf. (L@S '14). ACM, New York, NY, USA, 175-176.

[12] Danielle S. McNamara, L. Allen, S. Crossley, Mihai Dascalu, and Cecile A. Perret. 2017. Natural language processing and learning analytics. Handbook of learning analytics (2017), 93-104.

[13] Danielle S. McNamara, Irwin B. Levinstein, and Chutima Boonthum. 2004. iSTART: Interactive strategy training for active reading and thinking. Behavior Research Methods, Instruments, \& Computers 36, 2 (2004), 222-233.

[14] Audhesh K. Paswan and Joyce A. Young. 2002. Student Evaluation of Instructor: A Nomological Investigation Using Structural Equation Modeling. Fournal of Marketing Education 24, 3 (Dec. 2002), 193-202.

[15] Eline Sierens, Maarten Vansteenkiste, Luc Goossens, Bart Soenens, and Filip Dochy. 2009. The synergistic relationship of perceived autonomy support and structure in the prediction of self-regulated learning. British fournal of Educational Psychology 79, 1 (2009), 57-68. 